\title{
Prevalence of malnutrition and its associated factors among adult people living with HIV/AIDS receiving anti-retroviral therapy at Butajira Hospital, southern Ethiopia
}

\author{
Dereje Gedle ${ }^{1}$, Baye Gelaw², Dagnachew Muluye ${ }^{2}$ and Molla Mesele ${ }^{3}$
}

\begin{abstract}
Background: Malnutrition and human immunodeficiency virus/acquired immunodeficiency syndrome (HIV/AIDS) are highly prevalent in Sub-Saharan Africa, and they are linked in a vicious cycle. Intestinal parasite co-infection worsens the effect of malnutrition among HIV patients. However, the magnitude of malnutrition and its determinant factors among people living with HIV/AIDS are not well understood in Butajira in particular and Ethiopia in general. The aim of this study was to determine the prevalence of malnutrition and its associated factors among adult people living with HIV/AIDS and receiving anti-retroviral therapy (ART).
\end{abstract}

Methods: Institution-based cross-sectional study was conducted, and systematic random sampling technique was used to select study subjects. A total of 305 study subjects were enrolled in the study. Structured and pre-tested questionnaire was used to collect demographic data. From each sampled patient, anthropometric and laboratory data were also collected. Both bivariate and multivariate logistic regression analyses were used to assess the effect of the various factors on the level of malnutrition. A $P$ value $\leq 0.05$ at $95 \% \mathrm{Cl}$ was considered statistically significant.

Results: The overall prevalence of malnutrition was $25.2 \%$ of which 49,19 , and 9 patients were mildly, moderately, and severely malnourished, respectively. Multivariate logistic regression analysis revealed that living in rural area, anemia, and intestinal parasitic co-infection were significantly associated with malnutrition ( $A O R=1.98,1.9,2.85$, respectively).

Conclusions: The prevalence of malnutrition among HIV/AIDS patients receiving ART in Butajira was high and intestinal parasite co-infection was found as an important risk factor associated with malnutrition.

Keywords: Malnutrition, HIV/AIDS, ART, Intestinal parasites

\section{Background}

Globally, more than 800 million people are chronically undernourished [1], and over 35 million people are living with human immunodeficiency virus (HIV). Although new cases have been reported all over the globe, the majority of cases have been reported in low- and middle-income countries, particularly in Sub-Saharan Africa (SSA) [2]. In Ethiopia, $1.5 \%$ of adult people aged 15-49 are infected with HIV [3]. Malnutrition combined with human immunodeficiency virus/acquired immunodeficiency syndrome (HIV/

\footnotetext{
* Correspondence: tedybayegelaw@gmail.com

${ }^{2}$ Department of Medical Microbiology, College of Medicine and Health Sciences, University of Gondar, Gondar, Ethiopia

Full list of author information is available at the end of the article
}

AIDS) brought significant crisis in SSA in particular and globally in general. HIV affects the health status of an individual, and it has an impact on households, communities, and economic growth of the nations. In most developing countries, malnutrition together with infectious diseases aggravated the HIV/AIDS pandemic and contributed for both mortality and morbidity of patients [4,5]. HIV/AIDS and malnutrition effects are interconnected, worsen one another in a vicious cycle, and cause progressive damage to the immune system independently. HIV specifically affects nutritional status by reducing food intake, increasing energy requirements, and harmfully affects nutrient absorption and metabolism [6,7]. The effects of malnutrition by itself can decrease cluster of differentiation-four (CD4+) T cells 
and contribute to abnormal B-cell responses [8,9] which adversely affect the overall clinical outcome and exacerbate HIV-related immune depression [10].

Anti-retroviral therapy (ART) medications can cause nausea, vomiting, loss of appetite, diarrhea, and other disorders [11]. Diarrhea adversely affects the nutritional status of people living with HIV/AIDS (PLWHA) [12,13]. Commonly identified metabolic complications in adults living with HIV/AIDS who received ART include lipodystrophy, insulin resistance, dyslipidemia, lactic acidosis, and osteopenia $[14,15]$.

Adequate nutrition is necessary to manage opportunistic infections, maintain the immune system, optimize response to medical treatment, and support optimal quality of life for PLWHA [16]. Evidence has shown that good nutrition may contribute to slowing the progression of the disease. Nutrition interventions can also help to optimize the benefits of antiretroviral drugs and may increase compliance with treatment regimens [17].

The prevalence of malnutrition among PLWHA was reported higher in different parts of the world. In Ethiopia, malnutrition among PLWHA receiving ART has been a major challenge to accomplish the full impact of intervention. There are different reports that showed large magnitude of both HIV/AIDS and malnutrition in Ethiopia. However, the burden of malnutrition among PLWHA and receiving ART is not fully understood in Butajira Zonal administration in particular and in the nation in general. Moreover, determinants of nutritional status especially intestinal parasitic infection are not comprehensively studied. Hence, this study was designed to assess the prevalence of malnutrition and its associated factors among adult HIV/AIDS clients receiving ART at Butajira Hospital, Southern Ethiopia.

\section{Methods}

\section{Study area, design, and period}

The study was conducted at Butajira Hospital which is found in Butajira town, Gurage Zone, Southern Nations Nationalities and People's Region (SNNPR), located $135 \mathrm{~km}$ from the capital city, Addis Ababa, Ethiopia. The town lies on the average at 2,100 m above sea level. Butajira Hospital is a zonal hospital with 110 beds that gives health services for people living in Butajira and the surrounding rural kebeles. The study was an institutionbased cross-sectional study conducted from October 2013 to June 2014.

\section{Populations}

The source populations were all adult PLWHA in Butajira town and the surrounding area that were enrolled for ART follow-up service at Butajira Hospital. The study populations were people with the age of 18 years and above who were currently receiving ART. Patients who were receiving ART and involved in ART follow-up clinic at Butajira Hospital and aged 18 years and above were included in the study. However, pregnant women, lactating mothers (6 months of postpartum), and seriously ill and/or patients with spinal deformity were excluded.

\section{Operational definition}

Drug adherence status: it was estimated by percent of missed dose enclosed in the last 6 month follow-up time from patient ART follow-up form combined with selfreported adherence measurement technique by asking the patients about the number of times they have missed taking their pills each month and recorded. The category was based on WHO classification.

Good adherence: there is good adherence if the average adherence is greater than 95\% (he/she missed $\leq 2$ doses of 30 doses or $\leq 3$ doses of 60 doses).

Fair adherence: there is fair adherence if the average adherence is $85 \%-94 \%$ (he/she missed 3-5 doses of 30 doses or 3-9 doses of 60 doses).

Poor adherence: there is poor adherence if the average adherence is $<85 \%$ (he/she missed $\geq 6$ doses from 30 doses or $>9$ doses of 60 doses).

\section{Sample size and sampling technique}

The sample size was determined using single population proportion formula taking $22.1 \%$ [18] prevalence of malnutrition among adults with HIV/AIDS on ART with 5\% marginal error and 95\% confidence interval (CI) of certainty (alpha $=0.05$ ). In this study, $15 \%$ of non-response rate was taken, and the final sample size was determined as 305. A systematic random sampling technique was used to select the study subjects. According to the hospital report, on average, 10-20 patients that were currently taking ART have been visiting the hospital daily. Considering 3 months of study period, 660 patients were expected to visit the hospital. Since the sample size was determined as 305, the sampling interval was determined as 2. Of the first two subjects, one patient was randomly selected by lottery method; and then every second patient was selected to participate in the study.

\section{Socio-demographic data}

The data was collected from March to May 2014 using structured questionnaire. Socio-demographic characteristics were focused on data such as age, sex, monthly income, and educational and marital status together with nutrition and clinical-related characteristics were collected. Four data collectors (one nurse, one health officer, and two laboratory technicians) were recruited, and 2 days of training were given. The data collection process was followed daily by the principal investigator. 


\section{Laboratory data}

Data on opportunistic disease in the past 6 months, WHO clinical stages of disease, drug adherence, and chronic diseases were obtained from patient charts and ART follow-up forms. CD4+ T cell count was measured with BD FACS machine (US) and categorized according to its clinical significance. Hemoglobin was measured with Cell Dyne hematology analyzer (US). Hemoglobin level ranged between 13-17 and 12-16 g/dl was considered as normal for male and female patients, respectively. Patients were graded anemic when the hemoglobin concentration was $<12$ and $<13 \mathrm{~g} / \mathrm{dl}$ for male and female patients, respectively.

\section{Anthropometric data}

Anthropometric measurements (weight, height) were recorded by a trained nurse. Weight of the participants was measured in kilograms with $0.1 \mathrm{~kg}$ increments using standard beam balance, and the scale was checked at zero before and after each measurement. Each participant was asked to remove heavy clothes. Measurement of height was conducted using the standard measuring scale and recorded to the nearest $0.5 \mathrm{~cm}$. The participants were asked to take off their shoes, stand erect, and look straight in vertical plain.

\section{Stool sample collection and microscopy}

About $2 \mathrm{~g}$ of stool samples were collected in a clean leak-proof cupped plastic container following standard operating procedures. Each sample was examined by two clinical laboratory technicians independently for intestinal parasites using direct microscopic and concentration methods at Butajira Hospital parasitology laboratory. In the case of direct microscopic examination, stool samples were mixed with physiological saline $(0.85 \% \mathrm{NaCl})$ on a microscope slide, covered with a cover slip, and then examined microscopically using low power objective first and high dry power objective to examine cysts of intestinal parasites. In the case of formal-ether concentration method, about $2 \mathrm{~g}$ or $2 \mathrm{ml}$ of stool sample was mixed with $10 \mathrm{ml}$ of normal saline solution and thoroughly mixed. This was filtered through two layers of gauze into a centrifuge test tube and centrifuged for $1 \mathrm{~min}$ at a speed of approximately 25,000 rpm for $10 \mathrm{~min}$. When the supernatant fluid was very cloudy, the deposit was washed again by mixing it with $10 \mathrm{ml}$ of normal saline. After pouring or removing the supernatant fluid, $10 \mathrm{ml}$ of formaldehyde solution (10\% formalin solution) was added to the sediment. After mixing the suspension well and allowed to stand for $5 \mathrm{~min}, 3 \mathrm{ml}$ of ether was added and was immediately stopped and vigorously shacked for $30 \mathrm{~s}$. The preparation was centrifuged for $1 \mathrm{~min}$ at low speed, usually 1,500 rpm. There appeared four layers in the preparation; the first layer which is an ether, the second layer which is a debris, the third layer which is a formaldehyde solution, and the fourth layer which is the deposit containing stages of parasites (cysts, egg, and/or larvae). The supernatant was removed by tilting the tube and poured off all the fluid. The sediment was mixed with the remaining small fluid, and about two drops of the deposit was placed on a slide, to which a drop of iodine solution was added and covered with a cover slide. The entire preparation was examined using $\times 10 \mathrm{ob}-$ jective for protozoa eggs and $\times 40$ objective for cysts.

\section{Quality control}

The questionnaire was adapted and modified into our context from previous literatures. It was prepared first in English, translated into the local language Amharic, and then retranslated back to English by an expert to maintain its consistency. Training was given for data collectors and supervisor. Pre-testing of the questionnaire was made on 20 patients receiving ART in the nearby health center 3 weeks prior to the actual survey. Data collection process was strictly followed day to day by the supervisor and principal investigator. Standard operating procedures were followed during sample collection, processing, transportation, and identification of intestinal parasites. Data was checked for completeness, coded, and first entered in to EPI-info version 7; then, it was rechecked and transferred to Statistical Package for Social Science (SPSS) version 20 for analysis. Chi-square was used to carry out descriptive analysis. Bivariate and multivariate logistic regression analyses were used to assess the effect of the various factors on the level of malnutrition and to control possible confounders. The absence of multi-co-linearity was checked by using VIF/tolerance. The model adequacy was checked by using Hosmer and Lemeshow goodness of fit test. $P$ value $\leq 0.05$ at $95 \%$ CI was considered statistically significant.

\section{Ethical consideration}

Ethical approval was obtained from the ethical review committee of the School of Biomedical and Laboratory Sciences, College of Medicine and Health Sciences, University of Gondar, prior to data collection. Permission was taken from Butajira Zonal Hospital administrators. Written informed consent was obtained from each individual after the purpose of the study was explained. Participants were told that they had full right to participate or not, and they were also informed that all the data obtained from them would be kept confidential using codes instead of any personal identifiers. Any study participants who were positive for intestinal parasite were referred to ART clinicians for treatment. Finally, those 
participants identified as undernutrition were given nutritional counseling and RUTF in collaboration with the clinicians working in ART clinic at Butajira Hospital.

\section{Results}

\section{Socio-demographic characteristics of the study} participants

A total of 305 adult PLWHA receiving ART were involved in this study. The majority of participants (60.7\%) were in the age group 30-44 years with the mean and standard deviation $( \pm \mathrm{SD})$ of $39.5( \pm 9.9)$ years. Sixty-two percent of study participants were women, and more than half (50.5\%) of the study participants were currently married. The majority of participants (86.6\%) have low monthly income $(<1,000$ Ethiopian birr (ETB) as shown in (Table 1).

\section{Clinical profiles and ART status of the study participants} The HIV status of patients showed that $60.3 \%(n=184)$ were at WHO clinical stage I. One hundred twentyseven patients $(41.6 \%)$ had current or past history of opportunistic infections, of which 73 patients (23.9\%) had tuberculosis infection and accounted for the uppermost co-infection. The median CD4+ T cell count and mean hemoglobin concentration level of participants were 400 cells/ $\mu$ l with inter-quartile range (329 IQR) and $13.0 \mathrm{~g} / \mathrm{dl}$ with SD \pm 1.7 , respectively (Table 2). One hundred thirty-two patients $(43.3 \%)$ were on ART treatment regimen 1e (TDF + 3TC + NVP), and another $122(40 \%)$ were on 1c $(\mathrm{AZT}+3 \mathrm{TC}+\mathrm{NVP})$. However, quite a number of patients $(38.7 \%)$ had changed the ART regimen due to toxicity/side effects during follow-up period (Table 2).

\section{Nutrition-related characteristics of the study participants}

Data on the household food insecurity and dietary diversity status showed that $79 \%$ of participants were food insecure, of which 14 (4.6\%), 99 (32.5\%), and 128 (42\%) were mildly, moderately, and severely food insecure, respectively. The mean household dietary diversity was 4.93 with SD \pm 1.8 . Moreover, 121 (39.7\%) participants were with inadequate dietary diversity (Table 3 ).

Intestinal parasite infection among the study participants In this study, $26.6 \%$ of the study participants were coinfected with one or more intestinal parasites and six different types of intestinal parasitic species were identified. The prevalence of Entamoeba histolytica/dispar was $11.5 \%(n=35)$ and that of Taenia species $7.2 \%(n=$ 22 ) followed by Giardia lamblia 5.3\% $(n=16)$ (Table 4).

\section{Prevalence of malnutrition}

The overall prevalence of malnutrition (BMI $<18.5 \mathrm{~kg} /$ $\mathrm{m}^{2}$ ) among PLWHA receiving ART at Butajira Hospital was $25.2 \%$ (95\% CI: 20.0\%-30.2\%). Mild, moderate, and severe malnutrition were observed on 49 (16.1\%), 19 (6.2\%), and 9 (3.0\%) participants, respectively. The mean BMI for male and female was $20.77(\mathrm{SD} \pm 3.15)$ and 21.04 ( $\mathrm{SD} \pm 3.56$ ), respectively. The prevalence of malnutrition among male patients was 25.9\% (95\% CI: $18.3 \%-$ $34.3 \%$ ) but $24.9 \%$ (95\% CI: $18.8 \%-31.2 \%$ ) among females. The prevalence of malnutrition was also different by the age of the study subjects. Among 77 (25.2\%) malnourished subjects, the age group 30-44 were mostly affected, 42 (13.8\%), followed by the age group above 44 years, $29(9.5 \%)$.

\section{Factors affecting malnutrition}

In this study, both bivariate and multivariate logistic regression analysis were computed. Out of 11 selected variables that showed significant association with malnutrition in the bivariate model, only five variables (residence, eating difficulty, ready-to-use therapeutic food (RUTF), anemia, and intestinal parasitic infection) were significantly associated with malnutrition when data were computed with multivariate logistic regression analysis. Six variables that showed association on the bivariate model (age, educational status, gastrointestinal symptoms, diarrhea, Household Food Insecurity Access Scale (HFIS), and Household Dietary Diversity (HDD) were not statistically associated with malnutrition in the multivariate model (Table 5). In addition, being rural area dweller was significantly associated with malnutrition $(P=0.02)$. Patients living in rural area were two times more likely to be malnourished as compared to those living in urban areas $(\mathrm{AOR}=1.98$; 95\% CI: 1.10, 3.53). Eating difficulty was also positively associated with malnutrition $(P=0.002)$. Participants who had one or more eating difficulty were 2.69 times more likely to be malnourished as compared to those who were free of eating difficulty ( $\mathrm{AOR}=2.69$; 95\% CI: 1.41, 5.11). Ready-to-use therapeutic food (RUTF) was negatively associated with malnutrition. Individuals who were not taking RUTF were $82 \%$ times less likely to be malnourished than those who were taking RUTF $(\mathrm{AOR}=0.18 ; 95 \% \mathrm{CI}$ : $0.08,0.40)$. Anemia was also positively associated with malnutrition $(P=0.03)$. Participants who were anemic were 1.94 more likely to be malnourished than those with normal hemoglobin level ( $\mathrm{AOR}=1.94$; 95\% CI: 1.05, 3.57). Intestinal parasitic co-infection was also significantly associated with malnutrition. $(P=0.001)$. Participants who had one or more intestinal parasites were 2.85 times more likely to be malnourished as compared to those who were free of intestinal parasites $(\mathrm{AOR}=2.85 ; 95 \% \mathrm{CI}: 1.54,5.27$ ) (Table 5). 
Table 1 Socio-demographic characteristics of the study participants

\begin{tabular}{|c|c|c|c|}
\hline Characteristics & & Frequency (n) & Percent (\%) \\
\hline \multirow[t]{2}{*}{ Sex } & Male & 116 & 38.0 \\
\hline & Female & 189 & 62.0 \\
\hline \multirow[t]{3}{*}{ Age } & $18-29$ & 36 & 11.8 \\
\hline & $30-44$ & 185 & 60.7 \\
\hline & $\geq 45$ & 84 & 27.5 \\
\hline \multirow[t]{5}{*}{ Marital status } & Single & 19 & 6.2 \\
\hline & Married & 154 & 50.5 \\
\hline & Divorced & 42 & 13.8 \\
\hline & Widowed & 81 & 26.6 \\
\hline & Separated & 9 & 3.0 \\
\hline \multirow[t]{3}{*}{ Family size } & $\leq 3$ & 148 & 22.8 \\
\hline & $4-6$ & 137 & 21.1 \\
\hline & $>6$ & 20 & 3.1 \\
\hline \multirow[t]{5}{*}{ Educational status } & Unable to read and write & 121 & 39.7 \\
\hline & Able to read and write & 38 & 12.5 \\
\hline & Primary education & 80 & 26.2 \\
\hline & Secondary education & 47 & 15.4 \\
\hline & Tertiary education & 19 & 6.2 \\
\hline \multirow[t]{3}{*}{ Religion } & Orthodox & 143 & 46.9 \\
\hline & Muslim & 102 & 33.4 \\
\hline & Protestant and Catholic & 60 & 19.7 \\
\hline \multirow[t]{5}{*}{ Ethnicity } & Gurage & 178 & 58.4 \\
\hline & Silitie & 55 & 18.0 \\
\hline & Amhara & 40 & 13.1 \\
\hline & Oromo & 14 & 4.6 \\
\hline & Hadiya & 18 & 5.9 \\
\hline \multirow[t]{7}{*}{ Occupation } & Governmental employer & 40 & 13.1 \\
\hline & Self employer & 51 & 16.7 \\
\hline & Farmer & 39 & 12.8 \\
\hline & Merchant & 45 & 14.8 \\
\hline & Daily laborer & 60 & 19.7 \\
\hline & House wife & 49 & 16.1 \\
\hline & Jobless & 21 & 6.9 \\
\hline \multirow[t]{2}{*}{ Residence } & Urban & 177 & 58.0 \\
\hline & Rural & 128 & 42.0 \\
\hline \multirow[t]{2}{*}{ Monthly income in ETB } & $<1,000$ & 264 & 86.6 \\
\hline & $\geq 1,000$ & 41 & 13.4 \\
\hline
\end{tabular}

More than half of the patients were married, many had a family size of 4-6 members, and many were unable to read and write. The majority of the patients had less than 1,000 Ethiopian birr monthly income.

\section{Discussion}

This study is focused on assessing the prevalence of malnutrition and its associated factors among adult PLWHA and currently receiving ART. The overall prevalence of malnutrition $(25.2 \%)$ was relatively lower than other reports conducted in different parts of the world (37.2\%-43\%) [19-21].
The prevalence of malnutrition was also reported different in different parts of Ethiopia. For example, Hailemariam et al. reported a $12.3 \%$ prevalence of malnutrition in Dilla, southern parts of Ethiopia [22]. On the other hand, higher prevalence of malnutrition (42.3\%) was reported in Tigray, northern parts of Ethiopia [23]. The prevalence of 
Table 2 Clinical profiles and ART status

\begin{tabular}{|c|c|c|c|c|}
\hline \multicolumn{3}{|l|}{ Variables } & \multirow{2}{*}{$\frac{\text { Frequency }(\boldsymbol{n})}{235}$} & \multirow{2}{*}{$\begin{array}{c}\text { Percent (\%) } \\
77.0\end{array}$} \\
\hline Eating difficulty & No & & & \\
\hline & Yes & Problems & 70 & 23.0 \\
\hline & & Loss of appetite & 63 & 20.7 \\
\hline & & Vomiting & 20 & 6.6 \\
\hline & & Nausea & 13 & 4.3 \\
\hline & & Swallowing difficulty & 6 & 2 \\
\hline \multirow[t]{5}{*}{ Gastrointestinal symptoms } & No & & 255 & 83.6 \\
\hline & Yes & Problems & 50 & 16.4 \\
\hline & & Diarrhea & 28 & 9.2 \\
\hline & & Indigestion & 22 & 7.2 \\
\hline & & Constipation & 7 & 2.7 \\
\hline \multirow[t]{4}{*}{ WHO clinical stage } & Stage I & & 184 & 60.3 \\
\hline & Stage II & & 54 & 17.7 \\
\hline & Stage III & & 60 & 19.7 \\
\hline & Stage IV & & 7 & 2.3 \\
\hline \multirow[t]{4}{*}{ CD4+ T cell count } & $<200$ cells/ $\mu \mathrm{l}$ & & 51 & 16.7 \\
\hline & 200-350 cells/ $\mu \mathrm{l}$ & & 73 & 23.9 \\
\hline & $351-500$ cells $/ \mu l$ & & 76 & 24.9 \\
\hline & $>500$ cells $/ \mu l$ & & 105 & 34.4 \\
\hline \multirow[t]{2}{*}{ Anemia status } & Normal & & 220 & 72.1 \\
\hline & Anemic & & 85 & 27.9 \\
\hline \multirow[t]{9}{*}{ Current/past OI in the past 6 months } & No & & 178 & 58.4 \\
\hline & Yes & Problems & 127 & 41.6 \\
\hline & & Acute/chronic diarrhea & 45 & 14.8 \\
\hline & & Tuberculosis & 73 & 23.9 \\
\hline & & Oral thrush & 17 & 5.6 \\
\hline & & Oral ulcer & 8 & 2.6 \\
\hline & & Pneumonia & 8 & 2.6 \\
\hline & & Zoster & 3 & 1.0 \\
\hline & & Pneumocystis carinii & 1 & 0.3 \\
\hline \multirow[t]{6}{*}{ ART regimens } & $1 \mathrm{a}(\mathrm{d} 4 \mathrm{~T}+3 \mathrm{TC}+\mathrm{NVP})$ & & 7 & 2.3 \\
\hline & $1 c(A Z T+3 T C+N V P)$ & & 122 & 40.0 \\
\hline & $1 d(A Z T+3 T C+E F V)$ & & 14 & 4.6 \\
\hline & $1 e(T D F+3 T C+E F V)$ & & 132 & 43.3 \\
\hline & $1 f(T D F+3 T C+N V P)$ & & 26 & 8.5 \\
\hline & $2 b(T D F+3 T C+L P V / r)$ & & 4 & 1.3 \\
\hline \multirow[t]{4}{*}{ Duration of ART } & $<6$ months & & 38 & 12.5 \\
\hline & $6-12$ months & & 47 & 15.4 \\
\hline & $1-3$ years & & 53 & 17.4 \\
\hline & $>3$ years & & 167 & 54.8 \\
\hline \multirow[t]{2}{*}{ Regimen change } & No & & 187 & 61.3 \\
\hline & Yes & & 118 & 38.7 \\
\hline \multirow[t]{2}{*}{ Reasons for change } & Toxicity/side effect & & 117 & 38.4 \\
\hline & New tuberculosis & & 1 & 0.3 \\
\hline
\end{tabular}


Table 2 Clinical profiles and ART status (Continued)

\begin{tabular}{llrr}
\hline Drug adherence & Good & 277 & 90.8 \\
& Fair & 20 & 6.6 \\
& Poor & 8 & 2.6 \\
\hline
\end{tabular}

Many patients were on stage I HIV status, one-third had CD4+ T cell count less than 500 cells/ $\mu$, and more than half of the patients had a history of opportunistic infection. Many of the patients took ART treatment for more than 3 years but had toxicity/side effect. However, drug adherences for many of the patients were good enough.

AZT zidovudine, $d 4 T$ stavudine, EFV efavirenz, NVP nevirapine, TDF tenofovir, 3TC lamivudine, LPV/r lopinavir + ritonavir.

malnutrition in Gondar and Bahirdar, northwestern parts of Ethiopia, was reported $27.8 \%$ and $25.5 \%$, respectively $[18,24]$.The discrepancy of malnutrition among different parts of the country may reflect the existence of different socio-economic and other factors that are practiced by these different communities probably as a result of different ethnic experiences. The high prevalence of malnutrition reported in Tigray was only on women patients. This may indicate gender-dependent prevalence of malnutrition among HIV-positive women. There are also reports that support women are biologically, socially, and economically more vulnerable to both HIV/AIDS and malnutrition [25,26]. Women have lower muscle mass and greater amount of total body fat than men with an equivalent BMI, which may increase the prevalence of malnutrition, since sex and muscle mass can affect the relationship between BMI and body fat [27].

Patients living in rural area were two times more likely to be malnourished as compared to those living in urban areas. It will not be unwise to expect lower socioeconomic status, reduced awareness about nutrition, lower food access and diversity, and narrower availability of health, water, and sanitation services in rural dwellers than people living in urban in the study area as these are commonly observed in third world and developing countries. Eating difficulty was another significantly associated variable with malnutrition among PLWHA receiving ART. Participants who had one or more eating difficulty were 2.69 times more likely to be malnourished as compared to those who were free of eating difficulty. This finding is in accordance with the results of former studies conducted in Gondar and Bahirdar, northwestern Ethiopia [18,24]. Reduction of food consumption due to loss of appetite, vomiting and nausea due to the side effects of ART drugs, and swallowing difficulty due to oral thrush or ulcer lead to reduced energy intake and may also be the main reasons for the loss of weight among PLWHA [28].

This study found a significant positive association between anemia and malnutrition. Participants who were anemic were 1.94 times more likely to be malnourished than those with normal hemoglobin level. Similar

Table 3 Nutrition-related characteristics

\begin{tabular}{|c|c|c|c|}
\hline Variables & & Frequency $(n)$ & Percent (\%) \\
\hline \multirow[t]{2}{*}{ Change of feeding style after knowing HIV status } & No & 227 & 74.4 \\
\hline & Yes & 75 & 24.6 \\
\hline \multirow[t]{3}{*}{ Type of change of feeding style } & Frequency & 18 & 5.9 \\
\hline & Quality of food & 75 & 24.6 \\
\hline & Quantity & 3 & 1.0 \\
\hline \multirow[t]{2}{*}{ Dietary counseling } & No & 143 & 46.9 \\
\hline & Yes & 162 & 53.1 \\
\hline \multirow[t]{4}{*}{ Organizational support other than medication } & No & 263 & 86.2 \\
\hline & Economical support & 7 & 2.3 \\
\hline & RUTF & 26 & 8.5 \\
\hline & Economical and RUTF & 9 & 3.0 \\
\hline \multirow[t]{4}{*}{ Household food insecurity status } & Food secure & 64 & 21.0 \\
\hline & Mildly food insecure & 14 & 4.6 \\
\hline & Moderately food insecure & 99 & 32.5 \\
\hline & Severely food insecure & 128 & 42.0 \\
\hline \multirow[t]{2}{*}{ Household dietary diversity } & Inadequate & 121 & 39.7 \\
\hline & Adequate & 184 & 60.3 \\
\hline
\end{tabular}

Nearly half of the patients had no any type of dietary counseling, and many were severely food insecure. 
Table 4 Intestinal parasite co-infection

\begin{tabular}{|c|c|c|c|}
\hline Intestinal parasites & & Frequency $(n)$ & Percent (\%) \\
\hline Negative & & 224 & 73.4 \\
\hline Positive & & 81 & 26.6 \\
\hline \multirow[t]{4}{*}{ Protozoa's } & Entamoeba histolytica/dispar trophozoite & 22 & 7.2 \\
\hline & Entamoeba histolytica/dispar cyst & 13 & 4.3 \\
\hline & Giardia lamblia trophozoite & 14 & 4.6 \\
\hline & Giardia lamblia cyst & 2 & 0.7 \\
\hline \multirow[t]{4}{*}{ Helminthes } & Tanea species & 22 & 7.2 \\
\hline & Ascaris lumbricoides & 9 & 3.0 \\
\hline & Strongyloid stercoralis & 5 & 1.6 \\
\hline & Hookworm species & 2 & 0.7 \\
\hline \multirow[t]{3}{*}{ Multiple parasitic infections } & Entamoeba histolytica/dispar trophozoite + Giardia lamblia trophozoite & 2 & 0.7 \\
\hline & Entamoeba histolytica/dispar trophozoite + Ascaris lumbricoides & 2 & 0.7 \\
\hline & Giardia lamblia trophozoite + Tanea species & 1 & 0.3 \\
\hline
\end{tabular}

The prevalence of intestinal parasitic infection was $26.6 \%$. Entamoeba histolytica/dispar trophozoite and Tanea species were the dominant intestinal parasites identified.

reports were documented in a study conducted in Tigray [23]. This association of anemia with malnutrition might be due to alterations in bone marrow and spleen erythropoiesis, diminution in reticulocyte as a result of protein-energy malnutrition. Haemopoietic tissue has a high rate of regeneration, and cellular proliferation presents a high demand for protein for the process of haemopoiesis. Bone marrow atrophy is common in protein-energy malnutrition, which results from abnormalities of stem cells or defects in stromal cells, which would alter the haemopoietic microenvironment [29].

There was also a significant negative association between RUTF with malnutrition in the current study. Individuals who were not taking RUTF were $82 \%$ times less likely to be malnourished than those who were taking RUTF, and this was also in accordance with previous reports [23]. However, the current result on the association of RUTF with malnutrition contradicts with a report from other countries such as Central Haiti [30] and Uganda [31]. A number of reasons can contribute for the difference including the study design. The former studies conducted in Central Haiti were prospective cohort study, which have enough time to observe the potential effect of RUTF on that of malnutrition. On the other hand, the participants of the current study may not take RUTF properly due to sharing to their family members, selling to get money, and they may not respond to RUTF due to recurrent opportunistic infections, clinical stages of disease, and others.

The other pertinent finding of the current study was a highly significant positive association of intestinal parasites with malnutrition. Participants who had one or more intestinal parasites were 2.85 times more likely to be malnourished as compared to those who were free of intestinal parasites. This positive association might be due to nutrient demand of parasite itself, frequent episode of diarrhea and reduced appetite, blocking of the absorbing surface of the mucosa by adult worms, and altered absorption of nutrients [32,33]. Many of the populations at high risk for HIV also live in highly endemic areas of intestinal parasitic infections, which are mainly acquired in childhood and remain as chronic infections into adulthood [34]. Several investigators reported lower levels of hemoglobin as a result of pathogenic intestinal parasitic infections [35]. Entamoeba histolytica leads to necrosis of intestinal mucosa and bleeding; Giardia lamblia to malabsorption; and Tricuris is suggested to associate with anemia mediating through iron deficiency caused by blood loss [36]. Infection by hookworm causes iron deficiency anemia, and Ascaris lumbricoides is known to influence nutritional status; but its impacts on anemia are less clear [37].

The limitation of the current study could be the study design as cross-sectional study design by its nature limits information about cause and effect relationship in the majority of predictors. Recall bias and social desirability bias were the limitations of the study when measuring adherence to HAART and duration of HART. Moreover, only anthropometric measurement (BMI) was used to assess the nutritional status of participants, which assess mainly the public health burden of malnutrition. The study did not add some laboratory methods used to assess nutritional status like micronutrient deficiencies.

\section{Conclusions}

This study revealed that malnutrition is high among PLWHA receiving ART in Butajira Hospital, southern Ethiopia. Living in rural area, eating difficulty, anemia, 
Table 5 Factors associated with malnutrition among PLWHA receiving ART

\begin{tabular}{|c|c|c|c|c|c|}
\hline \multirow[t]{2}{*}{ Predictors } & \multicolumn{2}{|c|}{ Undernutrition } & \multirow[t]{2}{*}{ COR $(95 \% \mathrm{Cl})$} & \multirow[t]{2}{*}{ AOR $(95 \% \mathrm{CI})$} & \multirow[t]{2}{*}{$P$ value } \\
\hline & Yes & No & & & \\
\hline \multicolumn{6}{|l|}{ Age } \\
\hline $18-29$ & 6 & 30 & 1 & & \\
\hline $30-44$ & 42 & 143 & $1.47(0.57-3.76)$ & & \\
\hline$>44$ & 29 & 55 & $2.64(0.98-7.06)$ & & \\
\hline \multicolumn{6}{|l|}{ Residence } \\
\hline Urban & 35 & 142 & 1 & 1 & \\
\hline Rural & 42 & 86 & $1.98(1.17-3.34)$ & $1.98(1.10-3.53)$ & 0.02 \\
\hline \multicolumn{6}{|l|}{ Educational status } \\
\hline Unable to read and write & 40 & 81 & $2.63(0.72-9.57)$ & & \\
\hline Able to read and write & 12 & 26 & $2.46(0.60-10.08)$ & & \\
\hline Primary education & 16 & 64 & $1.33(0.35-5.14)$ & & \\
\hline Secondary education & 6 & 41 & $0.78(0.17-3.50)$ & & \\
\hline Tertiary education & 3 & 16 & 1 & & \\
\hline \multicolumn{6}{|l|}{ Eating difficulty } \\
\hline Yes & 29 & 41 & $2.76(1.56-4.88)$ & $2.69(1.41-5.11)$ & 0.002 \\
\hline No & 48 & 187 & 1 & 1 & \\
\hline \multicolumn{6}{|l|}{ Drug adherence } \\
\hline Yes & 18 & 32 & $1.87(0.98-3.57)$ & & \\
\hline No & 59 & 196 & 1 & & \\
\hline \multicolumn{6}{|l|}{ Diarrhea } \\
\hline Yes & 12 & 16 & $2.45(1.10-5.43)$ & & \\
\hline No & 65 & 212 & 1 & & \\
\hline \multicolumn{6}{|l|}{ RUTF } \\
\hline Yes & 22 & 13 & 1 & 1 & \\
\hline No & 55 & 215 & $0.15(0.07-0.3)$ & $0.18(0.08-0.40)$ & 0.00 \\
\hline \multicolumn{6}{|l|}{ Anemia } \\
\hline Yes & 31 & 54 & $2.17(1.25-3.76)$ & $1.94(1.05-3.57)$ & 0.03 \\
\hline No & 46 & 174 & 1 & 1 & \\
\hline \multicolumn{6}{|l|}{ HFIS } \\
\hline Food secure & 6 & 58 & 1 & & \\
\hline Mildly food insecure & 2 & 12 & $1.61(0.29-8.97)$ & & \\
\hline Moderately food insecure & 26 & 73 & $3.44(1.33-8.92)$ & & \\
\hline Severely food insecure & 43 & 85 & $4.89(1.95-12.2)$ & & \\
\hline \multicolumn{6}{|l|}{ HDD } \\
\hline Inadequate & 37 & 84 & $1.59(0.94-2.67)$ & & \\
\hline Adequate & 40 & 144 & 1 & & \\
\hline \multicolumn{6}{|l|}{ Intestinal parasite } \\
\hline Present & 33 & 48 & $2.81(1.62-4.89)$ & $2.85(1.54-5.27)$ & 0.001 \\
\hline Absent & 44 & 180 & 1 & 1 & \\
\hline
\end{tabular}


RUTF, and intestinal parasite co-infection were the most significant factors affecting malnutrition. Strengthening household food security status of patients besides nutritional support and ART treatment, consistent detection of intestinal parasites and prompt treatment or de-worming, and regular checkup of hemoglobin concentration among PLWHA in general and those taking ART in particular is recommended.

\section{Competing interests}

The authors declare that they have no competing interests.

\section{Authors' contributions}

DG participated in the conception and design of the study and coordinated the data collection and analysis. BG, DM, and MM assisted in critically reviewing the proposal, design of the study, and data analysis. BG prepared the manuscript for publication. All authors read and approved the final manuscript.

\section{Acknowledgements}

We would like to thank the Butajira Hospital ART and laboratory staffs for al the help and support given for us during the data collection and laboratory investigation. We also thank Mr. Zenebe Gedle, Mr. Dargaze Kibru, Mr. Yantenew Gedle, and Mr. Getnet Mekuriya for their immense advice and help in collecting the data and in investigating the laboratory samples.

\section{Author details}

${ }^{1}$ School of Biomedical and Laboratory Sciences, College of Medicine and Health Sciences (CMHS), University of Gondar (UOG), Gondar, Ethiopia. ${ }^{2}$ Department of Medical Microbiology, College of Medicine and Health Sciences, University of Gondar, Gondar, Ethiopia. ${ }^{3}$ Institute of Public Health, CMHS, UOG, Gondar, Ethiopia.

Received: 15 July 2014 Accepted: 11 December 2014

Published: 17 February 2015

\section{References}

1. Ivers LC, Cullen KA, Freedberg KA, Block S, Coates J, Webb P, et al. HIV/AIDS, undernutrition, and food insecurity. Clin Infect Dis. 2009;49(7):1096-102.

2. UNAIDS. Global Report 2012: UNAIDS Report on the Global AIDS Epidemic. 2013 [ebookpartnership.com]

3. CSA. Ethiopia demographic and health survey. Addis Ababa: Central Statistical Agency and ICF International USAID; 2011.

4. Anabwani G, Navario P. Nutrition and HIV/AIDS in sub-Saharan Africa: an overview. Nutrition. 2005;21(1):96-9.

5. Garcia-Prats AJ, McMeans AR, Ferry GD, Klish WJ. Nutrition and HIV/AIDS. HIV Curriculum. 2010;286:4-5.

6. WHO. Nutrient requirements for people living with HIV/AIDS: report of a technical consultation. Geneva: World Health Organization; 2003.

7. Piwoz E, Coursen-Neff Z, Penn A, Brooks L, Vann B, Beatty M, et al. Nutrition and HIV/AIDS: evidence gaps and priority actions. AWHONN Lifelines. 2004;8 (4):295-6.

8. Gorbach SL, Knox TA, Roubenoff R. Interactions between nutrition and infection with human immunodeficiency virus. Nutr Rev. 1993;51(8):226-34.

9. Scrimshaw NS, SanGiovanni JP. Synergism of nutrition, infection, and immunity: an overview. Am J Clin Nutr. 1997;66(2):464S-77.

10. Byron E, Gillespie S, Nangami M. Integrating nutrition security with treatment of people living with HIV: lessons being learned in Kenya. IFPRI. 2008;29(2):87-97

11. CATIE. A practical guide to HIV drug side effects for people living with HIV. In: Canada's source for HIV and hepatitis C: Canada. 1st ed. 2002.

12. Forrest G. Gastrointestinal infections in immunocompromised hosts. Curr Opin Gastroenterol. 2004;20(1):16-21.

13. Guerrant RL, Schorling JB, McAuliffe JF, De Souza MA. Diarrhea as a cause and an effect of malnutrition: diarrhea prevents catch-up growth and malnutrition increases diarrhea frequency and duration. AmJTrop Med Hyg. 1992;47(1 Pt 2):28-35.
14. Kim RJ, Rutstein RM. Impact of antiretroviral therapy on growth, body composition and metabolism in pediatric HIV patients. Pediatr Drugs. 2010;12(3):187-99.

15. Barbaro G. Highly active antiretroviral therapy-associated metabolic syndrome: pathogenesis and cardiovascular risk. Am J Ther. 2006;13(3):248-60.

16. Castleman T, Seumo-Fosso E, Cogill B. Food and nutrition implications of antiretroviral therapy in resource limited settings. Washington, DC: Fanta Project; 2003.

17. Bank W. HIV/AIDS, nutrition, and food security: what we can do. .: World Bank; 2013.

18. Daniel M, Mazengia F, Birhanu D. Nutritional status and associated factors among adult HIV/AIDS clients in Felege Hiwot Referral Hospital, Bahirdar, Ethiopia. Science. 2013:1(1):24-31.

19. Andrade CS, Jesus RP, Andrade TB, Oliveira NS, Nabity SA, Ribeiro GS Prevalence and characteristics associated with malnutrition at hospitalization among patients with acquired immunodeficiency syndrome in Brazil. PLoS One. 2012;7(11):e48717.

20. Hu W, Jiang $H$, Chen W, He SH, Deng B, Wang WY, et al. Malnutrition in hospitalized people living with HIV/AIDS: evidence from a cross-sectional study from Chengdu, China. Asia Pac J Clin Nutr. 2011;20(4):544-50

21. Sanon DA GN, Ann AC, Sow PS. Prevalence of malnutrition in a sample of people living with HIV-AIDS (PLWHA) with or without ART and to identify the risk factors associated with malnutrition. Geneva, Switzerland: Int AIDS Conf. 2006. XVI: Abstract no. MOPE0729.

22. Hailemariam S, Bune GT, Ayele HT. Malnutrition: prevalence and its associated factors in people living with HIV/AIDS, in Dilla University Referral Hospital. Arch Public Health. 2013;71(1):13.

23. WHO. Physical status: the use and interpretation of anthropometry. In: In report of a WHO expert Committee. vol. 854th ed. Edited by series WTR. Geneva: WHO; 2004

24. Hadgu TH, Worku W, Tetemke D, Berhe H. Undernutrition among HIV positive women in Humera Hospital, Tigray, Ethiopia, 2013: antiretroviral therapy alone is not enough, cross sectional study. BMC Public Health. 2013;13(1):943.

25. Friis $H$. Micronutrients and HIV infection: a review of current evidence, consultation on Nutrition and HIV/AIDS in Africa: Evidence, lessons and recommendations for action. Durban, South Africa: Department of Nutrition for Health and Development World Health Organization; 2005.

26. Borelli P, Blatt S, Pereira J, Beutler de Maurino B, Tsujita M, Cristina de Souza $A$, et al. Reduction of erythroid progenitors in protein-energy malnutrition. Br J Nutr. 2007;97(02):307-14.

27. Louise YC, Gregory JJ, Kenneth AF. Food assistance is associated with improved body mass index, food security and attendance at clinic in an HIV program in central Haiti. a prospective observational cohort study. AIDS Res Ther. 2011;7(33):1-8.

28. Rawat R, Kadiyala S, McNamara PE. The impact of food assistance on weight gain and disease progression among HIV-infected individuals accessing AIDS care and treatment services in Uganda. BMC Public Health. 2010;10 (1):316.

29. Jardim-Botelho A, Brooker S, Geiger SM, Fleming F, Souza Lopes AC, Diemert DJ, et al. Age patterns in undernutrition and helminth infection in a rural area of Brazil: associations with ascariasis and hookworm. Tropical Med Int Health. 2008;13(4):458-67.

30. Ngzuyen NL, Gelaye B, Aboset N, Kumie A, Williams MA, Berhane Y. Intestinal parasitic infection and nutritional status among school children in Angolela. Ethiopia J Prev Med Hyg. 2012;53(3):157-64.

31. Infectious disease society of America (IDSA). HIV/TB co-infection: basic facts. The Forum for collaborative HIV research. Virginia, USA: IDSA; 2007.

32. Sharam S, Mohan A. Co-infection of human immunodeficiency virus (HIV) and tuberculosis: Indian perspective. Ind J Tuberc. 2004;51:5-16.

33. Sharma S, Mohan A, Kadhiravan T. HIV/TB co-infection: epidemiology, diagnosis and treatment. Indian J Med Res. 2005:121(4):550-67.

34. Alzain B, Sharama P. Hemoglobin levels and protozoan parasitic infection in school children of Udaipur city (India). J Al Azhar Univ-Gaza (Na Sci). 2006;8:35-40

35. Stephenson $\mathrm{L}$. The public health significance of Tricuris trichuria. Parasitology. 2000;121:73-95. 
36. Cromoton D, Stenphenson L. In Hookworm infection, nutritional status and productivity. In: Chad GA, Warren K, editors. . Philadelphia: Taylor and Francos; 1990. 1: 236-245.

37. Osazuwa F, Michael A, Paul I. A significant association between intestinal helminth infection and anemia burden in children in rural communities of Edo state, Nigeria. N Am J Med Sci. 2011;3(1):30-4.

doi:10.1186/2055-0928-1-5

Cite this article as: Gedle et al:: Prevalence of malnutrition and its associated factors among adult people living with HIV/AIDS receiving anti-retroviral therapy at Butajira Hospital, southern Ethiopia. BMC Nutrition 2015 1:5.

\section{Submit your next manuscript to BioMed Central and take full advantage of:}

- Convenient online submission

- Thorough peer review

- No space constraints or color figure charges

- Immediate publication on acceptance

- Inclusion in PubMed, CAS, Scopus and Google Scholar

- Research which is freely available for redistribution 